\title{
Acute effect of pretreatment with single conventional dose of salmeterol on dose-response curve to oxitropium bromide in chronic obstructive pulmonary disease
}

\author{
Mario Cazzola, Felice Di Perna, Stefano Centanni, Clara Califano, Claudio Ferdinando \\ Donner, Maria D'Amato, Gennaro D'Amato
}

A. Cardarelli Hospital, Division of

Pneumology and Allergology, Naples,

Italy

M Cazzola

F Di Perna

C Califano

M D'Amato

G D'Amato

University of Milan, Medical School, San Paolo Hospital, Respiratory Diseases Unit, Milan, Italy S Centanni

S Maugeri Foundation, Institute of Care and

Research, Medical

Centre of

Rehabilitation,

Division of

Pneumology, Veruno,

Italy

C F Donner

Correspondence to:

Dr M Cazzola, Via del Parco

Margherita 24, 80121

Napoli, Italy

Received 16 April 1999

Returned to authors

14 July 1999

Revised manuscript received

29 July 1999

Accepted for publication

17 August 1999

\begin{abstract}
Background-An earlier study documented that, in patients with chronic obstructive pulmonary disease (COPD), addition of ipratropium bromide at the clinically recommended dose $(40 \mu \mathrm{g})$ does not produce any further bronchodilation than that achieved with salmeterol $50 \mu \mathrm{g}$ alone. However, the dose of ipratropium bromide needed to produce near maximal bronchodilation is several times higher than the customary dosage. The full therapeutic potential of combined salmeterol plus an anticholinergic drug can therefore only be established using doses higher than those currently recommended in the marketing of these agents. A study was undertaken to examine the possible acute effects of higher than conventional doses of an anticholinergic agent on the single dose salmeterol induced bronchodilation in patients with stable and partially reversible COPD.
\end{abstract}

Methods-Thirty two outpatients received $50 \mu \mathrm{g}$ salmeterol or placebo. Two hours after inhalation a dose-response curve to inhaled oxitropium bromide $(100 \mu \mathrm{g} / \mathrm{puff})$ or placebo was constructed using one puff, one puff, two puffs, and two puffs-that is, a total cumulative dose of $600 \mu \mathrm{g}$ oxitropium bromide. Dose increments were given at 20 minute intervals with measurements being made 15 minutes after each dose. On four separate days all patients received one of the following: (1) $50 \mu \mathrm{g}$ salmeterol $+600 \mu \mathrm{g}$ oxitropium bromide; (2) $50 \mu \mathrm{g}$ salmeterol + placebo; (3) placebo $+600 \mu \mathrm{g}$ oxitropium bromide; (4) placebo + placebo.

Results-Salmeterol induced a good bronchodilation (mean increase $0.2721 ; 95 \%$ CI 0.207 to 0.337 ) two hours after its inhalation. Oxitropium bromide elicited an evident dose-dependent increase in forced expiratory volume in one second $\left(\mathrm{FEV}_{1}\right)$ and this occurred also after pretreatment with salmeterol with a further mean maximum increase of 0.1521 (95\% CI of differences 0.124 to 0.180 ).

Conclusions-This study shows that acute pretreatment with $50 \mu \mathrm{g}$ salmeterol does not block the possibility of inducing more bronchodilation with an anticholinergic agent when a higher than normal dosage of the muscarinic antagonist is used.

(Thorax 1999;54:1083-1086)
Keywords: salmeterol; oxitropium bromide; combination therapy; chronic obstructive pulmonary disease

Recent British Thoracic Society guidelines for the management of stable chronic obstructive pulmonary disease (COPD) state that bronchodilators are the cornerstone of symptomatic treatment for the reversible component of airways obstruction. ${ }^{1}$ Short acting $\beta_{2}$ agonists used as required should be tried first in view of their more rapid relief of symptoms. If these do not control symptoms adequately or if regular maintenance therapy is desired, an anticholinergic agent can be added. This recommendation is based on the fact that anticholinergic and $\beta$ adrenergic agents, which are distinct classes of drugs with different mechanisms of action, are additive when used together. ${ }^{23}$

Long acting $\beta$ agonist bronchodilators such as formoterol and salmeterol are a new interesting therapeutic option for COPD. ${ }^{4-6}$ However, their impact on combinations is still unclear.

A combination of ipratropium with salmeterol $^{7}$ or formoterol ${ }^{8}$ in their normal dosages does not appear to improve pulmonary function, but this lack of improvement with the combination should not in itself prevent implementation of further therapeutic steps in patients responsive to ipratropium and/or salmeterol or formoterol administered singly.

In the present study we have investigated the possible acute effects of higher than normal doses of an anticholinergic agent on the single dose salmeterol induced bronchodilation in patients with stable and partially reversible COPD.

\section{Methods}

Thirty two outpatients with moderate to severe COPD but in a stable phase of the disease and with partially reversible airway obstruction were assessed. They gave their informed consent to participate in the study. All fulfilled the criteria proposed by the American Thoracic Society age, current or former smokers ( $>10$ pack years) without a history of asthmatic attacks, reporting chronic cough with or without sputum production and/or dyspnoea when walking quietly on level ground, or both; they had had no change in symptom severity or treatment in the preceding four weeks, had shown no signs of a respiratory tract infection 
Table 1 Anthropometric data and pulmonary function of patients

\begin{tabular}{|c|c|c|c|c|c|}
\hline Patient & Sex & Age (years) & $\begin{array}{l}F E V_{1} \\
\text { (\% predicted) }\end{array}$ & $\begin{array}{l}F V C \\
\text { (\% predicted) }\end{array}$ & $\begin{array}{l}\text { Reversibility } 15 \text { min } \\
\text { after } 200 \mu \mathrm{g} \text { salbutamol } \\
\text { (\% increase in } \mathrm{FEV} V_{1} \\
\text { from baseline) }\end{array}$ \\
\hline 1 & $\mathrm{~F}$ & 62 & 48 & 51 & 15 \\
\hline 2 & M & 66 & 30 & 45 & 18 \\
\hline 3 & M & 73 & 36 & 39 & 17 \\
\hline 4 & M & 55 & 48 & 55 & 18 \\
\hline 5 & M & 61 & 29 & 34 & 31 \\
\hline 6 & M & 58 & 36 & 48 & 21 \\
\hline 7 & $M$ & 71 & 19 & 24 & 18 \\
\hline 8 & $\mathrm{~F}$ & 70 & 55 & 69 & 17 \\
\hline 9 & M & 65 & 42 & 60 & 25 \\
\hline 10 & M & 57 & 37 & 44 & 21 \\
\hline 11 & M & 68 & 58 & 65 & 15 \\
\hline 12 & $\mathrm{~F}$ & 62 & 20 & 27 & 24 \\
\hline 13 & M & 68 & 33 & 36 & 15 \\
\hline 14 & M & 69 & 44 & 54 & 23 \\
\hline 15 & M & 58 & 29 & 36 & 19 \\
\hline 16 & M & 61 & 47 & 61 & 16 \\
\hline 17 & $\mathrm{~F}$ & 73 & 43 & 44 & 17 \\
\hline 18 & M & 67 & 40 & 58 & 15 \\
\hline 19 & M & 64 & 38 & 53 & 27 \\
\hline 20 & M & 65 & 25 & 32 & 28 \\
\hline 21 & $\mathrm{~F}$ & 71 & 50 & 61 & 26 \\
\hline 22 & M & 55 & 33 & 39 & 24 \\
\hline 23 & M & 63 & 47 & 60 & 19 \\
\hline 24 & M & 68 & 55 & 56 & 16 \\
\hline 25 & $\mathrm{~F}$ & 74 & 45 & 51 & 18 \\
\hline 26 & M & 72 & 43 & 49 & 20 \\
\hline 27 & M & 68 & 18 & 29 & 18 \\
\hline 28 & M & 64 & 22 & 25 & 15 \\
\hline 29 & $\mathrm{~F}$ & 62 & 33 & 35 & 19 \\
\hline 30 & $\mathrm{~F}$ & 58 & 49 & 55 & 17 \\
\hline 31 & M & 65 & 21 & 28 & 19 \\
\hline 32 & $M$ & 64 & 41 & 57 & 28 \\
\hline
\end{tabular}

$\mathrm{FEV}_{1}=$ forced expiratory volume in one second; $\mathrm{FVC}=$ forced vital capacity.

in the month preceding or during the trial, had not been taking oral or inhaled corticosteroids for at least three months, and had a forced expiratory volume in one second $\left(\mathrm{FEV}_{1}\right)$ of $<65 \%$ of predicted normal and a forced vital capacity (FVC) of $<70 \%$ after bronchodilators had been withheld for 24 hours and a best post-bronchodilator $\mathrm{FEV}_{1} / \mathrm{FVC}$ of less than 0.7. Patients with allergic rhinitis, atopy, positive skin test, or with a total blood eosinophil count over $400 \mathrm{~mm}^{-3}$ were excluded. Patients were also excluded if they had any co-existing cardiovascular or lung disorder. At an initial screening visit patients were required to demonstrate an increase in $\mathrm{FEV}_{1}$ of at least $15 \%$ from baseline to inhaled $200 \mu \mathrm{g}$ salbutamol. Table 1 outlines the baseline characteristics of the population studied.

No oral bronchodilators were permitted for one week before and during the study while inhaled short acting bronchodilator drugs and inhaled long acting bronchodilator agents were not permitted for at least 12 hours and 24 hours, respectively, before each test. Patients were also asked to refrain from consumption of cola drinks, coffee, tea, and smoking in the 12 hours before and during the investigation.
The study, which was conducted according to the rules of the declaration of Helsinki, was performed using a randomised, double blind, crossover design. Patients received two puffs of salmeterol $(25 \mu \mathrm{g} /$ puff $)$ or placebo inhaled from matched metered dose inhalers (MDI) and a holding chamber (AeroChamber) with a mouthpiece. Although oxitropium bromide and placebo could have been given by nebuliser, we chose MDI dosing for this study because salmeterol is not available as a solution and a double blind study would otherwise have not been possible.

Spirometric testing was performed according to the procedures described in the American Thoracic Society's 1987 update. ${ }^{10}$ Three acceptable forced expiratory manoeuvres were performed in order to obtain two reproducible results for FVC and $\mathrm{FEV}_{1}$. The higher of the two $\mathrm{FEV}_{1}$ results was kept for analysis. Measurements were performed immediately before inhalation of treatment and after two hours.

Two hours after the inhalation of salmeterol or placebo spirometric tests were performed in each patient, after which a dose-response curve to inhaled oxitropium (100 $\mu \mathrm{g} / \mathrm{puff})$ or placebo was constructed using one puff, one puff, two puffs, and two puffs - that is, a total cumulative dose of $600 \mu \mathrm{g}$ oxitropium. Oxitropium or placebo were administered from an MDI and holding chamber (AeroChamber) with a mouthpiece. Dose increments were given at 20 minute intervals with measurements being made 15 minutes after each dose. On four non-consecutive days all patients received one of the following: (1) $50 \mu \mathrm{g}$ salmeterol $+600 \mu \mathrm{g}$ oxitropium bromide, (2) $50 \mu \mathrm{g}$ salmeterol + placebo, (3) placebo $+600 \mu \mathrm{g}$ oxitropium bromide, or (4) placebo + placebo.

The increases in the functional indices from baseline after salmeterol or placebo were assessed. The $\mathrm{FEV}_{1}$ value induced by $600 \mu \mathrm{g}$ oxitropium bromide or placebo (six puffs) was chosen as the primary outcome variable. With an estimation of the within subject variability (residual standard deviation) of 0.101 , this crossover study with 32 patients had $80 \%$ power to detect a difference of at least 0.081 between treatments.

Analysis of spirometric data for each treatment was performed using the Student's $t$ test for paired variables. Mean responses were also compared by multifactorial analysis of variance (ANOVA) to establish any significant overall effect between all four treatments. In the presence of a significant overall ANOVA, Duncan's multiple range testing with $95 \%$ confidence

Table 2 Mean (95\% CI) baseline values and changes in FEV and FVC two hours after placebo (P) or $50 \mu \mathrm{g}$ salmeterol (S), and changes from values at 2 hours after 6 puffs of oxitropium bromide (OB) or placebo (P). Values are mean (95\% CI)

\begin{tabular}{|c|c|c|c|c|}
\hline & $P+P$ & $P+O B$ & $S+P$ & $S+O B$ \\
\hline \multicolumn{5}{|l|}{$\mathrm{FEV}_{1}(1)$} \\
\hline Baseline & $1.16(1.02$ to 1.30$)$ & $1.17(1.02$ to 1.32$)$ & $1.15(1.01$ to 1.29$)$ & $1.14(1.00$ to 1.28$)$ \\
\hline Mean change from baseline after 2 hours & $0.00(-0.04$ to 0.03$)$ & $0.00(-0.08$ to 0.07$)$ & $0.25(0.19$ to 0.31$)$ & $0.27(0.21$ to 0.34$)$ \\
\hline Mean change from value at 2 hours after 6 puffs of $\mathrm{OB}$ or $\mathrm{P}$ & $0.01(-0.03$ to 0.04$)$ & $0.27(0.21$ to 0.33$)$ & $0.03(0.00$ to 0.06$)$ & $0.15(0.12$ to 0.18$)$ \\
\hline \multicolumn{5}{|l|}{ FVC (1) } \\
\hline Baseline & $2.05(1.84$ to 2.27$)$ & $2.02(1.78$ to 2.26$)$ & $1.97(1.75$ to 2.19$)$ & $1.98(1.78$ to 2.28$)$ \\
\hline Mean change from baseline after 2 hours & $-0.03(-0.15$ to 0.09$)$ & $0.01(-0.06$ to 0.08$)$ & $0.23(0.14$ to 0.30$)$ & $0.18(0.08$ to 0.28$)$ \\
\hline Mean change from values at 2 hours after 6 puffs of OB or $\mathrm{P}$ & $0.02(-0.05$ to 0.09$)$ & $0.19(0.05$ to 0.33$)$ & $0.02(-0.09$ to 0.13$)$ & $0.06(-0.09$ to 0.20$)$ \\
\hline
\end{tabular}




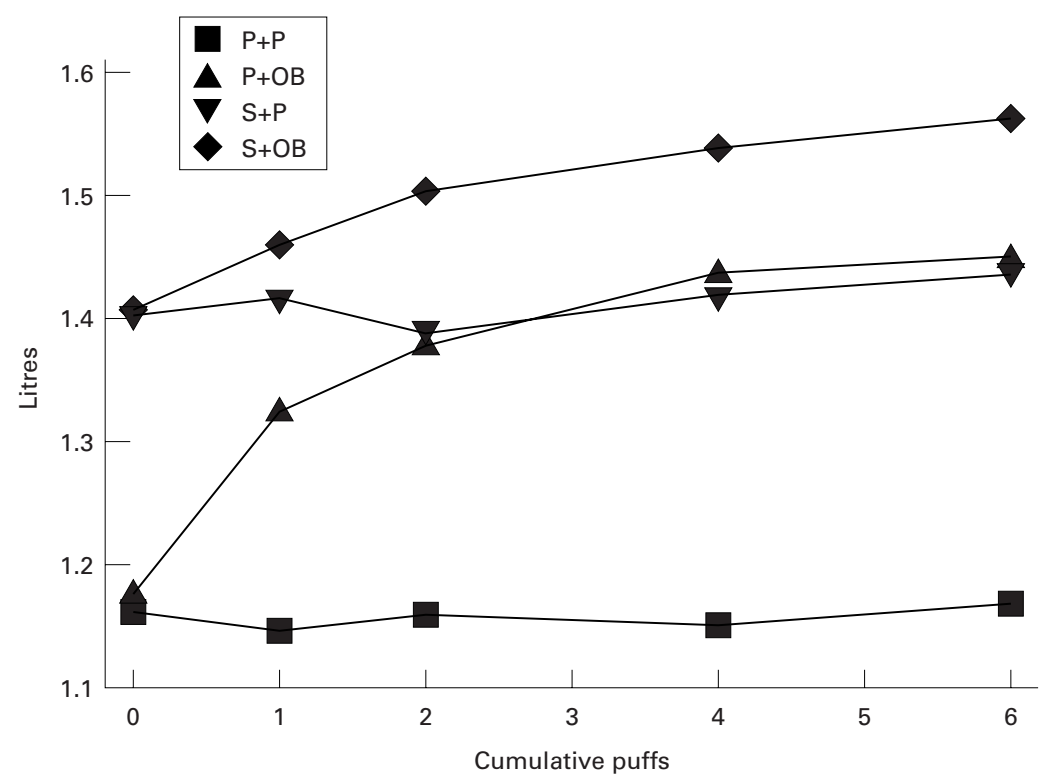

Figure 1 Mean dose-response curves to inhaled oxitropium bromide (OB) or placebo (P) constructed two hours after inhaling placebo or $50 \mu \mathrm{g}$ salmeterol (S) for FEV.

limits was used to identify where differences were significant. A probability level of $p<0.05$ was considered significant for all tests.

\section{Results}

All patients completed the four day study. There were no significant differences between the baseline spirometric values of the four treatment groups $\left(\mathrm{FEV}_{1}, \mathrm{p}=0.411\right)$

Salmeterol induced a significant bronchodilation two hours after its inhalation (mean increase $0.2721 ; 95 \% \mathrm{CI}$ of differences 0.207 to 0.337 ) whereas placebo did not modify the baseline values (table 2).

In the dose-response curve (fig 1) oxitropium but not placebo elicited an evident increase in $\mathrm{FEV}_{1}$. Specifically, the further mean maximum increase induced by $600 \mu \mathrm{g}$ oxitropium after pretreatment with $50 \mu \mathrm{g}$ salmeterol was 0.1521 (95\% CI of differences 0.124 to $0.180)$. Maximum values of bronchodilation induced by $600 \mu \mathrm{g}$ oxitropium after pretreatment with $50 \mu \mathrm{g}$ salmeterol or placebo were always statistically different $(p<0.0001)$ from their baseline and post-inhalational values (table 2).

Analysis of variance of $\mathrm{FEV}_{1}$ values induced by $600 \mu \mathrm{g}$ oxitropium bromide or placebo (six puffs) across all four treatments was significant $(\mathrm{p}=0.002)$. The comparison between salmeterol $+600 \mu \mathrm{g}$ oxitropium and salmeterol + placebo (six puffs) showed a mean difference of 0.1281 (95\% CI of differences 0.096 to 0.159$)$ that was statistically significant $(p<0.0001)$. The mean difference between the highest $\mathrm{FEV}_{1}$ after salmeterol $+600 \mu \mathrm{g}$ oxitropium and that after placebo $+600 \mu \mathrm{g}$ oxitropium was also statistically significant $(\mathrm{p}<0.01)$. In fact, the increase in $\mathrm{FEV}_{1}$ induced by $600 \mu \mathrm{g}$ oxitropium after pretreatment with salmeterol tended to be greater than that after placebo $(0.1111 ; 95 \%$ CI of differences 0.044 to $0.177)$. It should also be noted that treatment with $200 \mu \mathrm{g}$ oxitropium after salmeterol was significantly $(p<0.01)$ more effective than
$200 \mu \mathrm{g}$ oxitropium after placebo $(0.124$ 1; $95 \%$ CI of differences 0.075 to 0.173 ).

No patient complained of adverse symptoms (palpitations or significant increased heart rate) or reported any difference in the taste of the inhalers.

\section{Discussion}

A number of clinical studies have shown the benefit of adding a $\beta$ agonist to an anticholinergic agent such as ipratropium in COPD. ${ }^{11}$ Combination therapy with an inhaled anticholinergic and $\beta$ agonist may be more effective in bronchodilation than either of the two agents alone. ${ }^{12}$ In particular, several studies have reported that standard doses of short acting $\beta_{2}$ agonists do not give optimal results in patients with COPD and that an anticholinergic agent gives additional bronchodilation. ${ }^{13-15}$

The introduction of long acting $\beta$ agonist bronchodilators gives physicians additional therapeutic options for COPD, but their place in its treatment is currently not known. In any case, both salmeterol and formoterol appear to be more effective than short acting $\beta$ agonists ${ }^{16}$ and in patients with stable COPD salmeterol is more effective than anticholinergic agents. ${ }^{17} 18$

Unfortunately, use of combination therapy of a long acting inhaled $\beta_{2}$ agonist and an anticholinergic agent in COPD has not been sufficiently studied with respect to its effect on pulmonary function. In particular, a trial of an anticholinergic agent in patients with inadequate responsiveness to long acting $\beta_{2}$ agonists, especially in those with severe airflow obstruction, is lacking. To our knowledge there are only two published studies on small numbers of patients which found no substantial additive effect when a long acting $\beta_{2}$ agonist was combined with ipratropium at the clinically recommended dose $(40 \mu \mathrm{g})$ in patients with COPD. Matera et al found that the peak response for $50 \mu \mathrm{g}$ salmeterol was greater than for $40 \mu \mathrm{g}$ ipratropium, but equivalent peak bronchodilation occurred with salmeterol and salmeterol plus ipratropium. Another study has recently reported that a regimen of $12 \mu \mathrm{g}$ formoterol plus $40 \mu \mathrm{g}$ ipratropium was superior to 40 or $80 \mu \mathrm{g}$ ipratropium, but no statistically significant difference was observed between the combination regimen and 12 or $24 \mu \mathrm{g}$ formoterol. $^{8}$ It is possible that the subjects studied in these two specific clinical situations were at the top of their bronchodilation response curve after inhalation of salmeterol or formoterol. However, it must also be stressed that the dose of ipratropium bromide needed to produce near maximal bronchodilation is several times higher than the normal dosage. ${ }^{19}$ Consequently, the full therapeutic potential of combined salmeterol or formoterol plus an anticholinergic drug can only be established using doses higher than those currently recommended in the marketing of antimuscarinic agents.

The results of the present study show that acute pretreatment with $50 \mu \mathrm{g}$ salmeterol does not block the possibility of inducing further bronchodilation with oxitropium bromide when a higher than normal dosage of the 
anticholinergic drug is used. Our data suggest that the inhalation of $600 \mu \mathrm{g}$ oxitropium may be required to achieve a further bronchodilation when inadequate relief is obtained after $50 \mu \mathrm{g}$ salmeterol.

In this study we used oxitropium bromide as the anticholinergic agent because it is an effective bronchodilator in COPD, ${ }^{20}{ }^{21}$ exhibits a certain dose response relationship, ${ }^{22}$ and, more important, $\mathrm{FEV}_{1}$ reaches a plateau after administration of a cumulative dose of only six puffs of oxitropium $(600 \mu \mathrm{g})$ in patients with COPD. ${ }^{19}$

In conclusion, the results of this study suggest that higher than normal doses of an anticholinergic drug must be used for further relief of bronchospasm in patients with COPD when a single conventional inhaled dose of salmeterol is given first. However, we should stress that this study remains an observation of an acute effect and is limited to the effects on airway obstruction. Further larger studies are needed to verify the impact of regularly scheduled salmeterol combined with higher than the conventional dosage of an anticholinergic agent on spirometric values. It will also be interesting to examine the impact of such a combination on dyspnoea, improvement in quality of life, exercise capacity, and activities of daily living.

The authors thank Dr Paolo Fina for statistical analysis.

This study received no funding from the pharmaceutical industry.

1 COPD Guidelines Group of the Standards of Care Committee of the BTS. BTS guidelines for the managepulmonary disease. Thorax 1997;52 (Suppl 5): S1-28.

2 Combivent Inhalation Aerosol Study Group. In chronic obstructive pulmonary disease, a combination of ipratropium and albuterol is more effective than either agent pium and albuterol is more

3 Levin DC, Little KS, Laughlin KR, et al. Addition of anticholinergic solution prolongs bronchodilator effect of beta 2 agonists in patients with chronic obstructive pulmobeta 2 agonists in patients with chronic obstructive pul
nary disease. Am $\mathcal{F}$ Med 1996;100 (Suppl 1A):40-8S.
4 Cazzola M, Spina D, Matera MG. The use of bronchodilators in stable chronic obstructive pulmonary disease. Pulm Pharmacol Ther 1997;10:129-44.

5 Cazzola M, Matera MG. Should long-acting $\beta_{2}$-agonists be considered an alternative first choice option for the treatment of stable COPD? Respir Med 1999;93:227-9.

6 Cazzola M, Donner CF, Matera MG. Long-acting $\beta_{2}$ agonists and theophylline in stable chronic obstructive pulmonary disease. Thorax 1999;54:730-6.

7 Matera MG, Caputi M, Cazzola M. A combination with clinical recommended dosages of salmeterol and ipratropium is not more effective than salmeterol alone in patients with chronic obstructive pulmonary disease. Respir Med 1996;90:497-9.

8 Sichletidis L, Kottakis J, Marcou S, et al. Bronchodilatory responses to formoterol, ipratropium, and their combination in patients with stable COPD. Int f Clin Pract 1999;53: $185-8$.

9 American Thoracic Society. Standards for the diagnosis and care of patients with chronic obstructive pulmonary disease. Am f Respir Crit Care Med 1995;152: S72-120.

10 American Thoracic Society. Standardization of spirometry: 1987 update. Am Rev Respir Dis 1987;136:1285-98.

11 Chapman KR. Clinical implications of anticholinergic bronchodilator therapy in COPD. Res Clin Forums 1991;13 (2 part 1):43-50.

12 Campbell S. For COPD a combination of ipratropium bromide and albuterol sulfate is more effective than albuterol base Arch Intern Med 1999;159:156-60.

13 Brown IG, Chan CS, Kelly CA, et al. Assessment of the clinical usefulness of nebulised ipratropium bromide in patients with chronic airflow limitation. Thorax 1984;39: $272-6$.

14 Marlin GE. Studies of ipratropium bromide and fenotero administered by metered-dose inhaler and aerosolized solution. Respiration 1986;50(Suppl 2):290-3.

15 Barros MJ, Rees PJ. Bronchodilator responses to salbutamol followed by ipratropium bromide in partially reversible airflow obstruction. Respir Med 1990;84:371-5.

16 Cazzola M, Santangelo G, Piccolo A, et al. Effect of salmeterol and formoterol in patients with chronic obstructive pulmonary disease. Pulm Pharmacol 1994;7: 103-7.

17 Matera MG, Cazzola M, Vinciguerra A, et al. A comparison of the bronchodilating effects of salmeterol, salbutamol and ipratropium bromide in patients with chronic obstructive pulmonary disease. Pulm Pharmacol 1995;8:267-71.

18 Cazzola M, Matera MG, Di Perna F, et al. A comparison of bronchodilating effects of salmeterol and oxitropium bromide in stable chronic obstructive pulmonary disease. Respir Med 1998;92:354-7.

19 Ikeda A, Nishimura K, Koyama H, et al. Comparative doseresponse study of three anticholinergic agents and fenoterol using a metered dose inhaler in patients with chronic obstructive pulmonary disease. Thorax 1995;50:62-6.

20 Peel ET, Anderson G. A dose response study of oxitropium bromide in chronic bronchitis. Thorax 1984;39:453-6.

21 Lal S, Eyre-Brook A, Mitra SK, et al. Oxitropium bromide in chronic bronchitis. Res Clin Forums 1991;13(2, part 2):29-36

22 Skorodin MS, Gross NJ, Moritz T, et al. Oxitropium bromide, a new anticholinergic bronchodilator. Ann Allergy 1986;56:229-32. 